\title{
Contribution of Current Comorbid Conditions to Carotid Artery Stenosis in Patients Undergoing Coronary Artery Bypass and Stroke Distribution in Carotid Artery Stenosis Groups
}

\author{
Mehmet Işık, ${ }^{1}$ Yusuf Velioğlu ${ }^{2}$ \\ ${ }^{1}$ Department of Cardiovascular Surgery, Meram Faculty of Medicine, Necmettin Erbakan University, Konya, Turkey; \\ ${ }^{2}$ Department of Cardiovascular Surgery, Faculty of Medicine, Abant Izzet Baysal University, Bolu, Turkey
}

\section{ABSTRACT}

Objective: The aim of this study was to contribute to the issue of "Who should we perform Doppler ultrasonography on?" and determine the contribution of comorbid diseases to the development of carotid artery stenosis (CAS) and preoperative CAS by examining comorbid diseases in patients undergoing coronary artery bypass graft operation (CABG) and also discussing the effect of carotid stenosis levels on postoperative stroke.

Method: Between 2011-2015, a total of 921 patients who underwent cardiac surgery retrospectively were examined. Of these, 594 CABG patients aged 60 and over who underwent preoperative carotid Doppler examination were analyzed.

Results: Sixty-five percent of patients were male, and $35 \%$ were female. The mean age was 69.3 years. Sixty-nine percent of patients were in the $0-29 \%$ stenosis group, $12.9 \%$ in the $30-49 \%$ group, $14.6 \%$ in the $50-69 \%$ group, $3 \%$ in the $70-99 \%$ group, and $0.3 \%$ in the $100 \%$ occlusion group. Peripheral artery disease (PAD), age, gender, and diabetes mellitus $(\mathrm{DM})$ were found to have significant $(P<0.05)$ effects on the occurrence of CAS. CAS increased by $0.9 \%$ with an increase of one year in age, $10.8 \%$ with the presence of $\mathrm{PAD}, 3 \%$ with male sex, $3.8 \%$ with presence of chronic obstructive pulmonery disease (COPD), $1.9 \%$ with presence of left main coronary disease (LMCAD), and $0.9 \%$ with presence of hypertension. In the decision tree analysis, the rate of $50 \%$ and above CAS in the presence of $\mathrm{PAH}+\mathrm{DM}$ and age older than 65 years was $62.5 \%$. Cerebrovascular accident (CVA) distribution was $2.1 \%$ in the $0-29 \%$ group, $2.5 \%$ in the $30-49 \%$ group, $4.5 \%$ in the $50-69 \%$ group, and $11.1 \%$ in the 70-99\% group. Postoperative CVA was not observed in 10 patients who underwent carotid endarterectomy (CE). Postoperative CVA developed in six patients with $50 \%$ or more stenosis who did not undergo CE.

Received May 5, 2021; accepted May 21, 2021.

Correspondence: Mehmet Işık, MD, Assistant Professor, Department of Cardiovascular Surgery, Meram Faculty of Medicine, Necmettin Erbakan University, 42080, Konya, Turkey, Telephone +90 5335507549 (e-mail: drmisik@botmail.com).
Conclusion: For the preoperative detection of CAS in patients undergoing $\mathrm{CABG}$, the association of advanced age, $\mathrm{PAD}, \mathrm{DM}$, male gender, COPD, LMCAD, and hypertension risk factors should be considered. We suggest that carotid screening should be performed in those over 65 years of age and with $\mathrm{PAD}+\mathrm{DM}$. Studies with large populations are needed to observe the effects of aortic atherosclerosis load, surgical procedure, and unilateral/bilateral CAS presence on the development of stroke in patients with severe CAS and postoperative CVA.

\section{INTRODUCTION}

Atherosclerosis is a multifactorial disease that can simultaneously involve one or more regions of the arterial system. The most common risk factors include age, diabetes mellitus, obesity, hypertension, gender, hyperlipidemia, smoking, lack of physical activity, and genetic susceptibility. Coronary artery disease (CAD) and carotid artery stenosis (CAS) are two health problems that have atheroschlorotic origin and their coexistence is important.

A strong association was found between increased carotid intima-media thickness and CAD, risk of ischemic stroke, and cardiovascular-caused death [Lorenz 2007; Gül 2010]. While the incidence of significant CAS was $2.8-22 \%$ in patients undergoing coronary artery bypass graft operation (CABG), the incidence of significant accompanying CAD in patients undergoing carotid endarterectomy (CE) was reported to be $28-40 \%$ [Liapis 2009].

The importance of CAS in CABG patients is due to the fact that the flow is nonpulsative during cardiopulmonary bypass $(\mathrm{CPB})$ and arterial blood pressure is below the physiological values. When severe CAS is added to these two conditions, the possibility of cerebral hypoperfusion increases.

It was reported that the majority of patients who underwent CE with CABG were asymptomatic, in terms of CAS [Snider 2000]. Therefore, preoperative detection of the presence of CAS becomes difficult. The aim of this study is to contribute to the issue of "Who should we perform Doppler ultrasonography on?" to determine the contribution of comorbid diseases on the development of CAS and preoperative CAS by examining these comorbid diseases in patients undergoing $\mathrm{CABG}$ and also discussing the effect of carotid stenosis levels on postoperative stroke. 


\section{MATERIAL AND METHOD}

A total of 921 patients, who underwent open heart surgery in our clinic between June 2011 and August 2015, retrospectively were analyzed. Of them, 530 isolated CABG cases underwent preoperative carotid artery Doppler examination and $64 \mathrm{CABG}+$ mitral ring/valve or aortic valve replacement cases were included in the study. CABG patients aged under 60 and operated under emergency conditions were excluded from the study since Doppler was not performed. (Figure 1) In addition, valve patients and aortic surgery cases that did not require CABG were excluded from the study. The demographic characteristics of the patients were obtained from file records and the hospital software system. (Table 1) Study approval (2021/84) was obtained from the Local Ethics Committee and written informed patient consent was obtained from each patient. The study was carried out in accordance with the principles of the Declaration of Helsinki.

Doppler routinely was performed by the same radiologist on all patients aged 60 and over who were about to undergo elective CABG. GE Logic S6 model color Doppler device and a 9-10 MHz linear transducer were used. Bilateral carotid arteries were examined along their extracranial axis with B-mode color and spectral Doppler. Stenosis degrees were recorded as \%. The diagnostic criteria used for Doppler were accepted criteria by radiologists [Grant 2003].

Patients were classified as 0\%-29\% (Group 1), 30\%-49\% (Group 2), 50\%-69\% (Group 3), 70\%-99\% (Group 4), and $100 \%$ stenosis (Group 5), according to the degree of stenosis. Age, gender, hypertension, diabetes mellitus, lower extremity peripheral artery disease $(\mathrm{PAD})$, chronic obstructive pulmonary disease (COPD), left main coronary disease (LMCAD), smoking, ejection fraction (EF), and number of distal bypasses were compared in terms of their effects on the development of CAS.

The preoperative diagnosis of PAD first was made by Doppler and then angiography imaging was performed in patients who were suspicious on claudicatio anamnesis or pulse examination. LMCAD was determined by coronary angiography and EF by preoperative echocardiography. Routine pulmonary function tests were performed preoperatively for all patients for diagnosis of COPD. COPD was accepted if F1/ FVC $<70 \%$. Preoperative recommendations were obtained for these patients by performing chest diseases consultation. Patients with diabetes mellitus and hypertension already were diagnosed and taking insulin, oral antidiabetic, and/or antihipertensive drugs.

CABG was performed on a pump-assisted working heart without cross-clamping and without cardioplegia in on-pump patients. A side clamp was used for proximal anastomoses. Cross clamps and cardioplegia were used in patients, who underwent valve surgery with CABG. Off-pump patients (CABG) were operated with a routine procedure. $\mathrm{CE}$ was applied after MRI angiography imaging was performed on patients with stenosis of $70 \%$ and above in the Doppler report. CE simultaneously was performed with CABG before the internal mammary artery was removed.

Patients who had ischemic stroke during the postoperative hospital stay were noted as having cerebrovascular accident
(CVA). Neurology consultation, CT, and diffusion MRI images were available for all of these patients. The diagnosis of patients with preoperative CVA anamnesis was clarified by consulting with neurology and the necessary recommendations were received.

Statistical analysis: Categorical variables are given as frequency and percentages. Continuous variables are given as mean and standard deviations. Ordinal logistic regression was used to model ordinal outcome carotid stenosis (Analysis 1). Carotid stenosis also was modeled with a mixed effects model (Analysis 2). A decision tree was obtained using J48 algorithm after 10 -fold cross-validation. Decision tree was created by Weka 8.9.1 (The University of Waikato, Hamilton, New Zealand) software. Other analyses were done with SAS University Edition 9.4 (SAS Institute Inc, Cary, NC). Alpha value was set as $<.05$.

In Analysis 1 and Analysis 2 data, the amount of impact was calculated numerically for each risk factor separately. Analysis 1 gives the Odds ratio of being in an upper stenosis group in terms of CAS grouping in the presence of a risk factor. In Analysis 2, the degree to which the stenosis in the carotid artery will increase as a percentage in the presence of risk factors was predicted. (Table 2)

In the decision tree analysis, calculations were made for variations in narrowness groups, if several risk factors are present together. In the figure, firstly stenosis ratio and then the first number in parentheses indicates the total number of patients who match this condition (have these risks), and the second number indicates the number of patients who are not included in this group (have these risks but are not part of this stenosis group). (Figure 2)

\section{RESULTS}

Sixty-five percent of patients were male, $35.1 \%$ were female, mean age was 69.3 years (range: $60-84$ ), mean EF was $49.3 \%$ (70-20), and mean distal bypass count was 3.4 (1-5). The number of off-pump patients was 202, and the number of on-pump patients was 392 (isolated CABG were 328, CABG + valve were 64). The mean CPB duration was calculated as 147.3 minutes in CABG + valve surgeries and 79.9 minutes in on-pump CABG. Sixty-nine percent of patients were Group 1, 12.9\% were Group 2, 14.6\% were Group 3, 3\% were Group 4, and 0.3\% were Group 5 CAS. Demographic data are given in Table 1 and detailed information about the groups are given in Table 3. (Table 3)

In both different analyses, the presence of PAD $(P=$ $0.0003)$ and the increase in age $(P=0.0001)$ had a significant effect on the occurrence of CAS. Gender and presence of diabetes were statistically significant in Analysis $2(P=0.04)$. Hypertension, LMCAD, and COPD were not found to have a statistically significant effect on the formation of CAS in both analyses, but it was observed that there were risk factors contributing to the development of CAS. No relationship was found between smoking, EF, and distal bypass count with the development of CAS. In Table 2, the amount of impact on CAS formation for each risk factor and the odds ratios of 


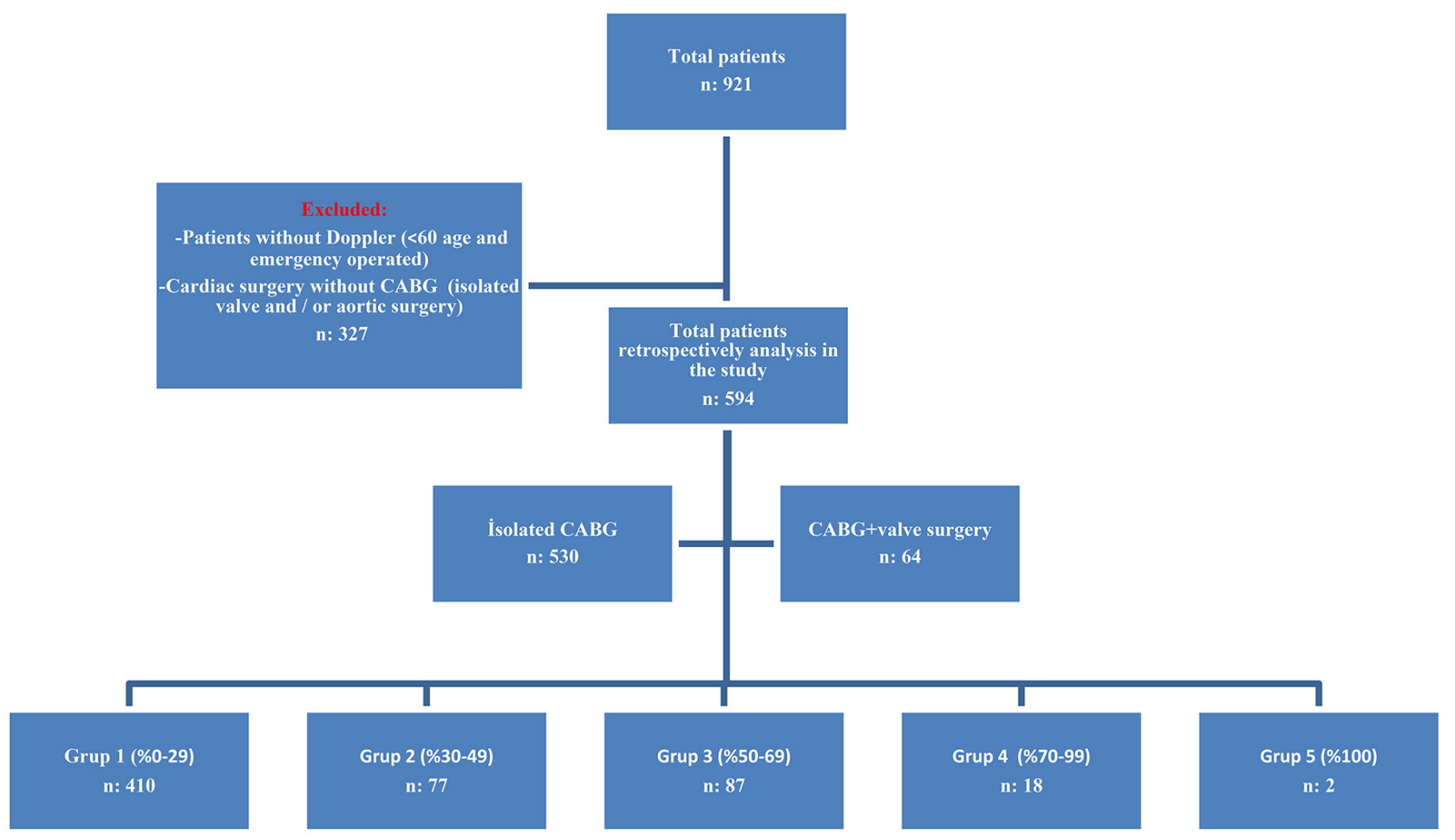

Figure 1. Study design and carotid stenosis groups.

Table 1. Demographic data and distal bypass numbers

\begin{tabular}{lcc}
\hline & Number of patients & Rate $\%$ \\
\hline Gender M/F & M: 386, F: 208 & M: 64.9, F: 35.1 \\
Hypertension & 279 & 47 \\
Diabetes mellitus & 223 & 37.7 \\
Smoke & 162 & 27.3 \\
LMCAD & 99 & 16.6 \\
PAD & 39 & 6.6 \\
COPD & 38 & 6.4 \\
EF (<\%50 / $2 \% 50)$ & $221 / 373$ & $37.2 / 62.8$ \\
Distal bypass numbers & & \\
1 & 16 & 2.6 \\
2 & 61 & 10.2 \\
3 & 196 & 33 \\
4 & 286 & 48.1 \\
5 & 35 & 5.8 \\
\hline
\end{tabular}

M, male; F, female; LMCAD, left main coronary artery disease; PAD, peripheral artery disease; COPD, chronic obstructive pulmonary disease; EF, ejection fraction

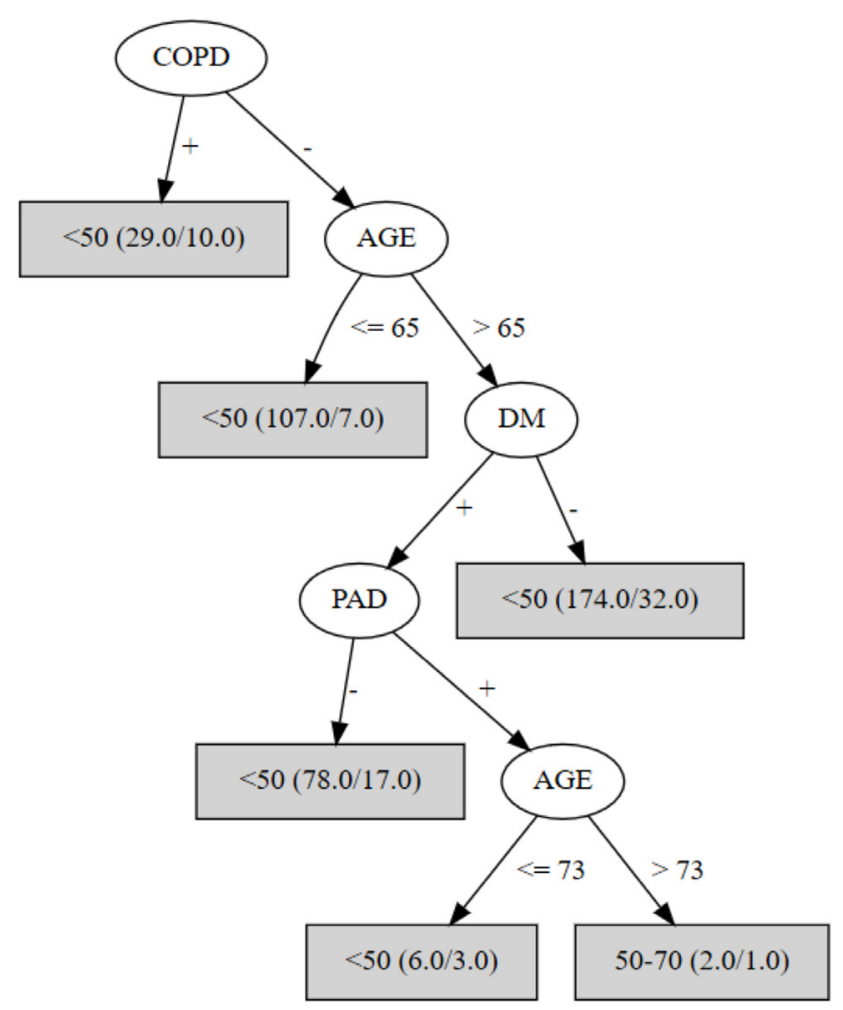

Figure 2. Decision tree analysis. COPD, chronic obstructive pulmonary disease; DM, diabetes mellitus; PAD, peripheral artery disease 
being in an upper stenosis group in terms of CAS stenosis grouping in the presence of the risk factor are given.

In the decision tree analysis, in $18.4 \%(N=32)$ of the patients older than 65 years without COPD and DM, 50\% and above CAS was present. In $21.7 \%(N=17)$ of the patients older than 65 years with $\mathrm{DM}$ but not $\mathrm{PAD}, 50 \%$ and above CAS was present. In $62.5 \%(N=5)$ of the patients with DM and PAD over 65 years of age, $50 \%$ and above CAS was detected. One of the two $(N=2)$ patients older than 73 years with both DM and PAD was in the $50-69 \%$ group and the other was in the $70-99 \%$ stenosis group.

In a total of 17 patients (2.8\%), CVA developed during the postoperative hospital stay (0-10 days). (Table 4) Sixteen of these were asymptomatic, and one patient had a history of preoperative CVA. The surgical distribution of patients with CVA was 12 isolated CABG (four off-pump and eight onpump) and five CABG + valve surgery. The CVA rate was found to be $1.9 \%$ in off-pump patients, $2.4 \%$ in on-pump patients, and $7.8 \%$ in CABG+valve surgeries. Preoperative diagnosis of CVA was present in 10 of 594 patients (1.6\%). Postoperative newly developing CVA was detected in only one of these patients.

Unilateral CE (six right and four left) was performed in 10 patients in the 70-99\% stenosis group. As surgical method, six primary closure and four saphenous patch plasties were applied. Five of these patients had bilateral CAS. Postoperative CVA was not detected in any of the patients who underwent CE. In six patients with $50 \%$ or more stenosis who did not undergo CE, postoperative CVA developed.

\section{DISCUSSION}

Possible causes of stroke after CABG include aortic atheroembolic events, atrial fibrillation, intracranial artery disease, and CAS. CAS is an important risk factor associated with postoperative stroke [Ülger 2011; Pinho-Gomes 2017]. At the present time, Doppler is frequently used to detect stenosis in the carotid artery. Doppler is a predominant method compared with angiography in the examination of plaque typing and flow changes and has sensitivity of $92.6 \%$ and specificity of $97 \%$ for evaluation of the carotid artery [Anzidei 2012].

In a study of CABG with carotid stenosis groups determined, stenosis was above $70 \%$ in $3.7 \%$ of cases, between $50-70 \%$ in $5.3 \%$, and below $50 \%$ in $91 \%$ [Rath 2001]. Ulger and colleagues [Ülger 2011] found occlusion in $2.7 \%$ of cases, stenosis of $70-99 \%$ in $3.7 \%$, and stenosis of $50-69 \%$ in $9 \%$. Of our patients, $0.3 \%$ were in the total occlusion group, $3 \%$ in the $70-99 \%$ stenosis group, $14.6 \%$ in the $50-69 \%$ stenosis group, $12.9 \%$ in the $30-49 \%$ stenosis group, and $69 \%$ of them had

Table 2. Statistical data

\begin{tabular}{|c|c|c|c|c|c|c|}
\hline \multirow[b]{2}{*}{ Risk factors } & \multicolumn{4}{|c|}{ Analysis 1} & \multicolumn{2}{|l|}{ Analysis 2} \\
\hline & $\begin{array}{l}\text { Odds ratio estimates (being in an } \\
\text { upper stenosis group odds ratio) }\end{array}$ & $95 \%$ Wal & nce Limits & $P$-value & Estimate (the amount of increase in \% stenosis) & $P$-value \\
\hline PAD & 2.723 & 1.441 & 5.143 & 0.0020 & 10.8176 & 0.0003 \\
\hline Diabetes & 1.290 & 0.884 & 1.881 & 0.1865 & 3.0351 & 0.0499 \\
\hline Hypertension & 1.220 & 0.855 & 1.741 & 0.2722 & 0.9881 & 0.4982 \\
\hline LMCAD & 1.150 & 0.727 & 1.818 & 0.5508 & 1.9424 & 0.6638 \\
\hline Age & 1.102 & 1.067 & 1.137 & $<0.0001$ & 0.9267 & $<0.0001$ \\
\hline
\end{tabular}

CAS, carotid artery stenosis; PAD, peripheral artery disease; COPD, chronic obstructive pulmonary disease; LMCAD, left main coronary artery disease

Table 3. Patients distribution and CVA rates according to CAS groups

$\begin{array}{lccccc}\text { CAS groups } & \text { Number of patients/ratio } & \text { Bilateral CAS } & \text { Right CAS } & \text { Left CAS } & \text { Number of patients with CVA/ratio } \\ \text { Group 1 } & 410(69 \%) & 61 & 2 & 2 & 9(2.1 \%) \\ \text { Group 2 } & 77(12.9 \%) & 17 & 34 & 26 & 2(2.5 \%) \\ \text { Group 3 } & 87(14.6 \%) & 10 & 3 & 21 & 4(4.5 \%) \\ \text { Group 4 } & 18(3.0 \%) & 13 & 1 & 2 & 2(11.1 \%) \\ \text { Group 5 } & 2(0.3 \%) & 1 & - & 0\end{array}$

CVA, cerebrovascular events; CAS, carotid artery stenosis 
less than $30 \%$ stenosis. In contrast to the above studies, the number of patients in the $50-69 \%$ stenosis group was higher and the number of total occlusions was less in our data. The probable cause of these differences might be related to the risk factors of patients and the duration of these risk factors.

As the average age of CABG patients increases, both clinically significant CAS is more common and stroke rates increase [D'Agostino 1996; Mohammed 2020]. In our study, CAS increased by $0.9 \%$ with the increase in patient age by one year, and the odds ratio of transfer into the upper carotid stenosis group increased by $1.1 \%$. It was reported that age increase is one of the strongest risk factors for atherosclerosis, aging affects IL-6 (interleukin-6) levels disrupting mitochondrial function in the aorta, and these changes cause atherosclerosis [Tyrrell 2020].

In a study including patients who underwent CABG in the Japanese population, none of the traditional atherosclerotic risk factors such as hypertension, hyperlipidemia, diabetes and smoking could predict CAS or PAD; however, CAS and PAD were independent predictors of each other [Kawarada 2003]. It was noted that the association of CAS and PAD in CABG patients is not only common, but they also have a strong relationship with each other [Kawarada 2003; Naylor 2002]. Among the risk factors in our study, the presence of PAD was the crucial risk factor that contributed to the formation of CAS. It was found that CAS increased by $10.8 \%$ in the presence of PAD, and the odds ratio of switching to an upper stenosis group in the presence of PAD was $2.7 \%$. The fact that CAS and PAD are diseases with an atherosclerosis origin and the separation of both arterial structures from the main arterial branch might be the cause of this crucial relationship. In addition, the presence of stenosis in both of these arteries, one of which is the proximal branch of the aorta and the other the distal branch, might be an indicator of common atherosclerosis or systemic atherosclerotic load in the aorta.

It is known that the predisposition for atherosclerosis is high in the male gender and that the tendency increases in women after the menopause and reaches a level close to the men at advanced ages [Lemne 1995]. Again, there was a strong correlation reported between the presence of diabetes and the development of CAS [Fabris 1994]. In our study, CAS increased by $3 \%$ in the presence of both risk factors (male gender and diabetes) separately and the odds ratio for switching to the next stenosis group was $1.2 \%$.

Associations of CAS with the presence of COPD, hypertension, and LMCAD were reported in different studies [Pinho-Gomes 2017; Lahousse 2013; Weber 2002; Hazar 2020]. In patients with COPD, carotid artery wall thickness was found to be higher than in the control group [Lahousse 2013], it was suggested that systolic blood pressure is a strong determinant of early CAS [Weber 2002], and that the incidence of CAS was higher in patients who underwent CABG due to LMCAD [Pinho-Gomes 2017]. As a result of the analysis of our data, carotid artery stenosis increased by $3.8 \%$ in the presence of COPD, increased by $1.9 \%$ in the presence of LMCAD, and increased by $0.9 \%$ in the presence of hypertension. The odds ratios of switching to a higher stenosis group were $1.2 \%, 1.1 \%$ and $1.2 \%$, respectively.

It was stated that while the perioperative stroke risk is less than $2 \%$ in patients who have planned CABG and no serious CAS preoperatively, it is $3.2 \%$ in patients with unilateral CAS $50-99 \%, 5.2 \%$ in those with bilateral $50-99 \%$, and $7-11 \%$ in those with occlusion [Kawarada 2003]. In our data, CVA ratio was $2.1 \%$ in patients with Group 1 stenosis, $2.5 \%$ in Group

Table 4. Distribution of patients with postoperative cerebrovascular events

\begin{tabular}{|c|c|c|c|c|c|c|c|c|c|c|c|c|}
\hline & $N$ & $\mathrm{M} / \mathrm{F}$ & Age & RCAS & LCAS & VD & $\mathrm{SD}$ & LHP & RHP & CABGO+Valve & $\mathrm{AF}$ & On pump \\
\hline Group 1 & 9 & $6 / 3$ & - & 2 & 1 & 3 & 1 & 3 & 2 & 2 & 2 & 8 \\
\hline Group 2 & 2 & & & & & & & & & & & \\
\hline Patient 1 & - & $M$ & 77 & $41 \%$ & - & - & - & Yes & - & Yes & Yes & Yes \\
\hline Patient 2 & - & $M$ & 82 & $45 \%$ & $45 \%$ & - & - & Yes & - & Yes & - & Yes \\
\hline Group 3 & 4 & & & & & & & & & & & \\
\hline Patient 1 & - & $\mathrm{F}$ & 62 & $50 \%$ & $62 \%$ & - & - & Yes & - & - & - & - \\
\hline Patient 2 & - & $M$ & 62 & $56 \%$ & - & Yes & - & - & - & - & - & Yes \\
\hline Patient 3 & - & $M$ & 63 & - & $59 \%$ & - & - & Yes & - & - & - & - \\
\hline Patient 4 & - & $M$ & 70 & $51 \%$ & $50 \%$ & - & - & Yes & - & - & - & Yes \\
\hline Group 4 & 2 & & & & & & & & & & & \\
\hline Patient 1 & - & $M$ & 84 & $70 \%$ & $69 \%$ & - & - & Yes & - & - & - & - \\
\hline Patient 2 & - & $M$ & 70 & $40 \%$ & $76 \%$ & - & - & - & Yes & Yes & - & Yes \\
\hline Group 5 & 0 & & & & & & & & & & & \\
\hline
\end{tabular}

$\mathrm{N}$, number of patients with cerebrovascular event; M, male; F, female; RCAS, right carotid artery stenosis; LCAS, left carotid artery stenosis; VD, vision disorder; SD, speech disorder; HP, hemiplegic; AF, atrial fibrillation 
2, $4.5 \%$ in Group 3, and $11.1 \%$ in Group 4 patients. Carotid artery disease itself is associated with atherosclerosis of the ascending aorta and is a possible risk factor for atheroembolic stroke after CABG [Pinho-Gomes 2017]. The multifactorial nature of post-CABG stroke and the similarity of imaging and clinical findings make it difficult to determine the specific cause of stroke. It is very difficult to distinguish whether the CVA increase rate in Group 4 patients is caused by CAS or by atheroembolism due to increased aortic atherosclerosis. Surgical strategies should be developed for patients at risk using preoperative carotid screening and aortic imaging.

It was reported that aortic atheroembolism might play a more important role in postoperative strokes in CABG patients with asymptomatic and unilateral CAS [Naylor 2018; Borger 2005]. In a meta-analysis study, while no obvious increase in the stroke ratio and death in patients with neurologically asymptomatic and severe unilateral CAS was reported depending on the degree of stenosis, there were increases in stroke and death ratios in bilaterally asymptomatic patients [Naylor 2011]. The importance of 50\% CAS and above is known [North American Symptomatic Carotid Endarterectomy Trial Collaborators 1991]. In our study, the number of patients with Group 3 and Group 4 stenosis and postoperative CVA was six. Neurological examination findings of one of the patients with unilateral CAS were not compatible with the side of CAS. In this patient, it can be said that CVA was not caused by CAS. In patients with bilateral stenosis, differentiation cannot be made by looking at the side of the symptom. It was observed that CVA developed at $5 \%$ in Group 3 patients with bilateral stenosis and 15.3\% in Group 4 patients.

In our previous study, CVA rate was $2 \%$ in patients who underwent off-pump CABG and $3 \%$ in patients who underwent on-pump beating heart CABG [Velioglu 2019]. In this study, the CVA rate was found to be $1.9 \%$ for off-pump CABG, $2.4 \%$ in patients with on-pump beating heart CABG, and $7.8 \%$ in patients who underwent on-pump CABG + valve surgery. We believe that the increase in the rate of combined surgeries is related to the surgical procedure and the duration of CPB because the duration of CPB in combined surgeries was longer than 66 minutes on average. Studies with large populations are needed to observe how the presence of severe CAS (with prolongation of time) affects CVA rates in patients undergoing $C A B G$ + valve surgery.

If $\mathrm{CE}$ is performed before $\mathrm{CABG}$ in patients with severe CAS, the risk of postoperative stroke is reduced by $40-50 \%$ [Rath 2001; Naylor 2002; Çayır 2020]. In our study, postoperative CVA developed in two patients with bilateral lesions who were in the $70-99 \%$ stenosis group and did not have CE performed due to patient-related reasons. Postoperative CVA was not detected in any of the 10 patients (five patients had bilateral lesions) who underwent CE. Currently, there are not many options to prevent atheroembolism caused by the aorta. In order to prevent CAS-induced CVS, we believe that preoperative detection and necessary treatment should be administered. In addition, it was reported that maintaining high arterial pressure during $\mathrm{CPB}$ in patients with CAS detected is a strategy that might prevent cerebral hypoperfusion [Gökşin 2005].
Carotid screening is recommended before CABG in the presence of various risk factors. Doppler scanning should be considered in patients over 70 years of age, and with a history of temporary ischemic attacks or stroke [Aboyans 2009]. In another study, carotid Doppler scanning before elective CABG was stated to be reasonable in patients over 65 years of age, with left main coronary stenosis, PAD, smoking history, stroke, or transient ischemic attack history [Brott 2011].

In our decision tree analysis to observe the change in the percentage of stenosis in the case of a combination of several risk factors, the number of patients with $50 \%$ and above stenosis increased with the addition of some comorbid conditions, especially in patients older than 65 years. In order to detect preoperative $50 \%$ and above CAS, carotid Doppler appears to be crucial in patients older than 65 years of age and with $\mathrm{PAD}+\mathrm{DM}$ association $(50 \%$ and above CAS was detected in $62.5 \%$ of these patients).

The limitations of the study are that it was a retrospective study, patients under the age of 60 were not included in the study due to not performing routine Doppler examination, the duration of smoking pack/year was unknown, the lipid profile was not included among the risk factors (since the hunger level was not known when the analysis was performed), and the presence of a relatively small amount of data for the decision tree analysis. Moreover, the number of patients was limited to be able to comment in the context of cause and effect on patients with CAS and postoperative CVA.

In conclusion, in order to prevent CAS-induced CVA, preoperative stenosis should be determined and surgical strategies appropriate for this situation should be determined. The associations of male gender, COPD, LMCAD and hypertension risk factors, especially advanced age, PAD and diabetes should be noted. We suggest that carotid screening should be performed in patients older than 65 years of age with PAD and DM association. In order to observe the effects of aortic atherosclerosis load, surgical procedure and unilateral/bilateral CAS on the development of stroke in patients with severe CAS and postoperative CVA, prospective studies with large populations are necessary. In addition, analysis involving more patients and risk factors is needed to support our decision tree analysis results and obtain strong scientific evidence.

\section{REFERENCES}

Aboyans V, Lacroix P. 2009. Indications for carotid screening in patients with coronary artery disease. Presse Med. 38:977-86.

Anzidei M, Napoli A, Zaccagna F, Di Paolo P, Saba L, Cavallo Marincola B, et al. 2012. [Article in English, Italian] Diagnostic accuracy of colour Doppler ultrasonography, CT angiography and blood-pool-enhanced MR angiography in assessing carotid stenosis: a comparative study with DSA in 170 patients. Radiol Med. 117:54-71.

Borger MA. 2005. Preventing stroke during coronary bypass: are we focussing on the wrong culprit? J Cardiac Surg. 20:58-9.

Brott TG, Halperin JL, Abbara S, Bacharach JM, Barr JD, Bush RL, et al. 2011. 2011 ASA/ACCF/AHA/AANN/AANS/ACR/ASNR/CNS/SAIP/ SCAI/SIR/SNIS/SVM/SVS Guideline on the Management of Patients with Extracranial Carotid and Vertebral Artery Disease: Executive 
Summary A Report of the American College of Cardiology Foundation/ American Heart Association Task Force on Practice Guidelines, and the American Stroke Association, American Association of Neuroscience Nurses, American Association of Neurological Surgeons, American College of Radiology, American Society of

Neuroradiology, Congress of Neurological Surgeons, Society of Atherosclerosis Imaging and Prevention, Society for Cardiovascular Angiography and Interventions, Society of Interventional Radiology, Society of NeuroInterventional Surgery, Society for Vascular Medicine, and Society for Vascular Surgery Developed in Collaboration with the American Academy of Neurology and Society of Cardiovascular Computed Tomography. J Am Coll Cardiol. 57:1002-44.

Çayır MÇ, Yüksel A. 2020. Local or general anesthesia for carotid endarterectomy: Which anesthesia technique should be preferred? J Surg Med. 4(3):195- 198.

D’Agostino RS, Svensson LG, Neumann DJ, Balkhy HH, Williamson WA, Shahian DM. 1996. Screening carotid ultrasonography and risk factors for stroke in coronary artery surgery patients. Ann Thorac Surg. 62:1714-23.

Fabris F, Zanocchi M, Bo M, Fonte G, Poli L, Bergoglio I, Ferrario E, Pernigotti L. 1994. Carotid plaque, aging, and riskfactors: A study of 457 subjects. Stroke. 25(6):1133-40.

Gökşin İ, Yağc1 B, Baltalarlı A, Özcan V, Saçar M, Gürses E, et al. 2005. Routine Preoperative Carotid Doppler Ultrasonography in Patients Undergoing Coronary Artery Bypass Grafting. Türkiye Klinikleri J Med Sci. 25:221-6.

Grant EG, Benson CB, Moneta GL, Alexandrov AV, Baker JD, Bluth EI, et al. 2003. Carotid artery stenosis: grayscale and Doppler ultrasound diagnosis-Society of Radiologists in Ultrasound consensus conference. Ultrasound Q. 19:190-8.

Gül K, Ustün I, Aydin Y, Berker D, Erol K, Unal M, et al. 2010. Carotid intima-media thickness and its relations with the complications in patients with type 1 diabetes mellitus. Anatol J Cardiol. 10:52-58.

Hazar A, Altinbaş Ö, Aydın MS, Koçarslan A. 2020. Usefulness of Radial Artery as a Carotid Artery Patch in Simultaneous Carotid Endarterectomy and Coronary Artery Bypass Graft Operation with Complete Arterial Revascularization. Heart Surg Forum. Oct 14;23(6):E752-E755.

Kawarada O, Yokoi Y, Morioka N, Nakata S, Higashiue S, Mori T, Iwahashi M, Hatada A. 2003. Carotid stenosis and peripheral artery disease in Japanese patients with coronary artery disease undergoing coronary artery bypass grafting. Circ J. Dec;67(12):1003-6.

Lahousse L, van den Bouwhuijsen QJ, Loth DW, Joos GF, Hofman A, Witteman JC, van der Lugt A, Brusselle GG, Stricker BH. 2013. Chronic obstructive pulmonary disease and lipid core carotid artery plaques in the elderly: the Rotterdam Study. Am J Respir Crit Care Med. Jan $1 ; 187(1): 58-64$.

Lemne C, Jogestrand T, Faire deU. 1995. Carotid intima-media thickness and plaque in borderline hypertension. Stroke. 26(1):34-9.
Liapis CD, Bell PR, Mikhailidis D, Sivenius J, Nicolaides A, Fernandes e Fernandes J, et al. 2009. ESVS guidelines. Invasive treatment for carotid stenosis: indications, techniques. Eur J Vasc Endovasc Surg. 37:1-19.

Lorenz MW, Markus HS, Bots ML, Rosvall M, Sitzer M. 2007. Prediction of clinical cardiovascular events with carotid intima-media thickness: a systematic review and metaanalysis. Circulation. 115:459-67.

Mohammed MEA, Alshahrani S, Zaman G, Alelyani M, Hadadi I, Musa M. 2020. Lipid profile, random blood glucose and carotid arteries thickness in human male subjects with different ages and body mass indexes. Aging Male. Jun 8:1-7.

Naylor AR, Bown MJ. 2011. Stroke after cardiac surgery and its association with asymptomatic carotid disease: an updated systematic review and meta-analysis. Eur J Vasc Endovasc Surg. 41:607-24.

Naylor AR, Mehta Z, Rothwell PM, Bell PRF. 2002. Carotif artery disease and stroke during coronery bypass: a critical review of the literature. Eur J Vasc Endovasc Surg. 23(4):283-94.

Naylor AR, Ricco JB, Borst GJ de, Debus S, Haro J de, Halliday A, et al. 2018. Editor's Choice - Management of Atherosclerotic Carotid and Vertebral Artery Disease: 2017 Clinical Practice Guidelines of the European Society for Vascular Surgery (ESVS). Eur J Vasc Endovasc Surg. 55,3-81.

North American Symptomatic Carotid Endarterectomy Trial Collaborators. 1991. Beneficial effect of carotid endarterectomy in symptomatic patients high with grade stenosis. N Engl J Med. 325:445-53.

Pinho-Gomes AC, Taggart DP. 2017. Coronary artery bypass grafting for left main disease and the risk of stroke: Incidence, aetiology and prevention. Surgeon. Jun;15(3):155-160.

Rath PC, Agarwala MK, Dhar PK, Lakshmi C, Ahsan SA, Deb T, et al. 2001. Carotid artery involvement in patients of atherosclerotic coronary artery disease undergoing coronary artery

bypass grafting. Indian Heart J. 53:761-5.

Snider F, Rossi M, Manni R, et al. 2000. Combined surgery for cardiac and carotid disease: Management and results of a rational approach. Eur J Vasc Endovasc Surg. 20:523-7.

Tyrrell DJ, Blin MG, Song J, Wood SC, Zhang M, Beard DA, Goldstein DR. 2020. Age-Associated Mitochondrial Dysfunction Accelerates Atherogenesis. Circ Res. Jan;31;126(3):298-314.

Ülger A, Şahin S, Bahadır FE, Uzunlulu N, Tuygun AK, Arslan Y, Bilgen F. 2011. Comparison of the incidences of carotid artery lesion and vertebrobasilary insufficiency with incidence of postoperative stroke in patients who undergo coronary artery bypass graft surgery. Turkish J Thorac Cardiovasc Surg. 19(2):127-137.

Velioglu Y, Isik M. 2019. Early-Term Outcomes of Off-Pump versus OnPump Beating-Heart Coronary Artery Bypass Surgery. Thorac Cardiovasc Surg. Oct;67(7):546-553.

Weber F. 2002. Risk factors for subclinical carotid atherosclerosis in healthy men. Neurology. 59(4):524-28. 